\title{
The Prevalence of Frailty and its Associated Risk Factors Among the Saudi Elderly Population in Primary Health Care in Riyadh, Saudi Arabia
}

\section{Abdulmalik Almufarrih*, Badr Almutairi, Nayef Alblowi, Saeed Asiri, Ahmad Alnashri, Saad Albattal, Medhat Maher and Mostafa Kofi}

Department of Family and Community Medicine, Prince Sultan Military Medical

City, Riyadh, Saudi Arabia

*Corresponding Author: Abdulmalik Almufarrih, Department of Family and Community Medicine, Prince Sultan Military Medical City, Riyadh, Saudi Arabia.
Received: November 03, 2021

Published: November 26, 2021

(C) All rights are reserved by Abdulmalik

Almufarrih., et al.

\section{Abstract}

Background: Frailty is a geriatric clinical syndrome characterized by increased vulnerability to a wide range of negative outcomes such as falls, disability, institutionalization, and mortality. Frailty is becoming a major public health issue as the population of the elderly continues to grow for developing future planning, intervention, and treatment for the targeted groups. As a result, the purpose of this study was to determine the prevalence of frailty in older adults and to identify risk factors for frailty, in Riyadh, Saudi Arabia.

Methods: A cross-sectional observational study was carried out in 2021 convenient sample of 228 from the elderly patients aged 60-year-old or above who are attending Al-Wazart health center of Prince Sultan Military Medical City, Riyadh, Saudi Arabia. A data collection form that consists of two parts, the first part assessed the patient demographics, comorbidities, and medications, while the second part consisted of the FRAIL scale and the Mini-cog test.

Result: A total of 228 Saudi elderly patients participated in the current study, the male gender represented $51.8 \%$ of the studied sample, and $42.1 \%$ were in the age group of 60-65 years old. The largest percentage $(43.4 \%)$ of the participants were in the BMI group of $25-29.9 \mathrm{~kg} / \mathrm{m}^{2}$, the vast majority (97.4\%) of them were nonsmokers, and living with their families (99.1\%). Almost one-third of the participants have a caregiver at $32.0 \%$, and $46.1 \%$ were illiterate. It was found that the prevalence of frailty was $25.4 \%$ while $24.6 \%$ were prefrail. There was a statistically significant difference $(\mathrm{P}<0.05)$ between the robust, frail, and prefrail subjects in terms of age, educational level, and presence of a caregiver.

Conclusion: The prevalence of frailty syndrome was $25.4 \%$, while $24.6 \%$ were prefrail. Possible cognitive impairment was reported in $18.4 \%$. Old age, dyslipidemia, heart failure, hypothyroidism, and polypharmacy, were the significant risk factors for frailty. As the older adults population size in Saudi Arabia is growing with greater longevity, the impact of frailty syndrome could not be ignored and neglected. Further study is needed to validate our findings in other large-scale population of older adults.

Keywords: Frailty; Elderly; Geriatric; Saudi Arabia

\section{Introduction}

Frailty is a geriatric clinical syndrome characterized by increased vulnerability to a wide range of negative outcomes such as falls, disability, institutionalization, and mortality as a result of decreased reserve and resistance to stressors caused by cumulative declines in multiple physiological systems [1]. Over the last few decades, research efforts have contributed to a better definition and description of frailty, but there is no gold standard for identi- 
fying frailty [2,3]. Unintentional weight loss, weakness, slowness, low physical activity level, and weariness are all components of the frailty phenotype suggested by Fried., et al. [1], and individuals who have three or more components are considered frail, while those who have none to two components are considered non-frail. Frailty syndrome is becoming more widely recognized as a major concern for the elderly. It is a silent process in an adult's life that distinguishes normal aging from disability [4].

Frailty is becoming a major public health issue as the population of the elderly continues to grow [5]. According to the United Nation report in 2017 [6], In Saudi Arabia, the elderly population is expected to increase significantly by the year 2050 to reach $22.9 \%$. Therefore, this would increase the prevalence of frailty as older adults are the most vulnerable group facing frailty.

Frailty was found in $4.0 \%$ to $59.1 \%$ of community-dwelling older adults [7]. Moreover, Frailty is quite common in elderly hospitalized patients, with prevalence rates ranging from 27 to $80 \%$ in [8-10]. Clinical frailty progression in older adults is complicated. It is not caused by a single factor but is commonly influenced by several factors that can be interrelated or independent of one another. Female gender, advanced age, living alone, low education level, low-income level, poor self-rated health, and having more chronic disease are among the associated factors commonly reported in the literature [11-[14]. Frailty is usually the result of many problems that culminate in an overall functional decline [15].

The identification of factors contributing to frailty syndrome may have implications for health practitioners, educators, and policymakers as a guide in terms of assessments, investigating etiologies, and predicting factors for developing future planning, intervention, and treatment for the targeted groups. A comprehensive approach to frailty and limitation prevention is thus required, focusing on modifiable individual and environmental risk factors before the condition progresses to the severe stage and becomes a disability. As a result, the purpose of this study was to determine the prevalence of frailty in older adults and to identify risk factors for frailty, in Riyadh, Saudi Arabia.

\section{Methods}

This was a cross-sectional study that has been conducted from January- July 2021 among Saudi elderly attending Al-Wazart health center of Prince Sultan Military Medical City, Riyadh, Saudi Arabia.
Al-Wazart health center is one of the biggest primary health care centers in Saudi Arabia with more than 50 clinics with different specialties, some of which are available 24/7. Every week, more than 8000 patients are checking in for a follow-up, screening, or management.

The current study population were recruited through convenience sampling from elderly patients aged 60-year-old or above who are attending Al-Wazarat Primary Healthcare Center at Prince Sultan Military Medical City, Riyadh, Saudi Arabia. Patients who are bed-ridden/wheelchair-bound have a language barrier, or inability to understand the study information and to give written informed consent due to (e.g. severe aphasia, severe cognitive impairment/ dementia, or severe visual or auditory impairment) and who has an acute illness were all excluded.

The data was collected by a data collection form that consists of two parts, the first part assessed the patient demographics, comorbidities, and medications, while the second part consisted of the FRAIL scale [16] and the Mini-cog test [17]. The FRAIL scale (short 5-question assessment of fatigue, resistance, aerobic capacity, illnesses, and loss of weight) classified the patients into 3 categories: robust (score $=0$ ), prefrail (score $=1-2$ ), and frail (score $=3-5$ ), it was translated to Arabic and adapted to Saudi elderly culture by Alqahtani BA., et al. [18]. The Mini-Cog test a composite of threeitem recall and clock drawing was developed as a brief test for discriminating demented from non-demented persons. It is a valid assessment tool that is widely used in clinical practice and research and was translated into Arabic by Albanna M., et al. [19]. The data collection process was carried out as Face-To-Face interviews and the interviewer filled the data collection form.

\section{Statistical analysis}

Data were analyzed by using Statistical Package for Social Studies (SPSS 22; IBM Corp., New York, NY, USA). Categorical variables were expressed as percentages. The Chi-square test was used for categorical variables. Univariate and multivariate logistic regression were used to assess the associated risk factors with frailty among the Saudi Elderly population. A p-value $<0.05$ was considered statistically significant.

\section{Results}

A total of 228 Saudi elderly patients participated in the current study, the male gender represented $51.8 \%$ of the studied sample, 
and $42.1 \%$ were in the age group of $60-65$ years old. The largest percentage $(43.4 \%)$ of the participants were in the BMI group of $25-29.9 \mathrm{~kg} / \mathrm{m}^{2}$, the vast majority (97.4\%) of them were nonsmokers, and living with their families (99.1\%). Almost one-third of the participants have a caregiver at $32.0 \%$, and $46.1 \%$ were illiterate. Data is shown in table 1.

\begin{tabular}{|c|c|c|c|}
\hline & & Number & $\%$ \\
\hline \multirow{5}{*}{ Age group } & $60-65$ & 96 & 42.1 \\
\hline & $66-70$ & 55 & 24.1 \\
\hline & $71-75$ & 42 & 18.4 \\
\hline & $76-80$ & 12 & 5.3 \\
\hline & $>80$ & 23 & 10.1 \\
\hline \multirow{6}{*}{ BMI } & $15-19.9$ & 1 & .4 \\
\hline & $20-24.9$ & 25 & 11.0 \\
\hline & $25-29.9$ & 99 & 43.4 \\
\hline & $30-34.9$ & 90 & 39.5 \\
\hline & $35-39.9$ & 11 & 4.8 \\
\hline & $>=40$ & 2 & .9 \\
\hline \multirow{2}{*}{ Gender } & Male & 118 & 51.8 \\
\hline & Female & 110 & 48.2 \\
\hline \multirow{5}{*}{$\begin{array}{l}\text { Education } \\
\text { level }\end{array}$} & illiterate & 105 & 46.1 \\
\hline & Primary & 55 & 24.1 \\
\hline & Elementary & 41 & 18.0 \\
\hline & High-school & 19 & 8.3 \\
\hline & Higher education & 8 & 3.5 \\
\hline \multirow{2}{*}{ Living Status } & Alone & 2 & .9 \\
\hline & Family & 226 & 99.1 \\
\hline \multirow{2}{*}{$\begin{array}{c}\text { Having a Care } \\
\text { giver }\end{array}$} & Yes & 73 & 32.0 \\
\hline & No & 155 & 68.0 \\
\hline \multirow{2}{*}{ Smoking } & Yes & 6 & 2.6 \\
\hline & No & 222 & 97.4 \\
\hline
\end{tabular}

Table 1: Characteristics of the participants.

The prevalence of frailty among the studied Saudi elderly population is shown in table 2 . It was found that the prevalence of frailty was $25.4 \%$ while $24.6 \%$ were prefrail.

The results of the current study showed that $18.4 \%$ of the Saudi elderly population might have possible cognitive deteriorations, as shown in table 3.

\begin{tabular}{|c|c|c|c|}
\hline & & Number & $\%$ \\
\hline \multirow[t]{2}{*}{ DM } & Yes & 189 & 82.9 \\
\hline & No & 39 & 17.1 \\
\hline \multirow[t]{2}{*}{ HTN } & Yes & 166 & 72.8 \\
\hline & No & 62 & 27.2 \\
\hline \multirow[t]{2}{*}{ Dyslipidemia } & Yes & 170 & 74.6 \\
\hline & No & 58 & 25.4 \\
\hline \multirow[t]{2}{*}{ Heart failure } & Yes & 27 & 11.8 \\
\hline & No & 201 & 88.2 \\
\hline \multirow[t]{2}{*}{ stroke } & Yes & 13 & 5.7 \\
\hline & No & 215 & 94.3 \\
\hline \multirow[t]{2}{*}{ osteoprosis } & Yes & 35 & 15.4 \\
\hline & No & 193 & 84.6 \\
\hline \multirow[t]{2}{*}{ Hypothyroidism } & Yes & 33 & 14.5 \\
\hline & No & 195 & 85.5 \\
\hline \multirow[t]{2}{*}{ CKD } & Yes & 9 & 3.9 \\
\hline & No & 219 & 96.1 \\
\hline \multirow[t]{2}{*}{ Depression } & Yes & 6 & 2.6 \\
\hline & No & 222 & 97.4 \\
\hline \multirow[t]{2}{*}{ Polypharmacy } & Yes & 96 & 42.1 \\
\hline & No & 132 & 57.9 \\
\hline
\end{tabular}

Table 2: Prevalence of Comorbidities among the participants.

\begin{tabular}{|l|c|c|}
\hline & Number & Prevalence (\%) \\
\hline Robust & 114 & 50.0 \\
\hline Pre-frail & 56 & 24.6 \\
\hline Frail & 58 & 25.4 \\
\hline
\end{tabular}

Table 3: Prevalence of frailty among the our study Elderly population.

Prevalence of frailty among the Saudi Elderly population by characteristics of the participants is shown in table 4 . There was a statistically significant difference $(\mathrm{P}<0.05)$ between the robust, frail, and prefrail subjects in terms of age, educational level, and presence of a caregiver.

The majority of the study participants were diabetic, hypertensive, and dyslipidemic at $82.9 \%, 72.8 \%$, and $74.6 \%$, respectively. Almost $15 \%$ of them were osteoporotic and have hypothyroidism, while $42.1 \%$ were polypharmacy, as shown in table 5. 


\begin{tabular}{|l|c|c|}
\hline & Number & Prevalence (\%) \\
\hline Possible deterioration & 42 & 18.4 \\
\hline No deterioration & 186 & 81.6 \\
\hline
\end{tabular}

Table 4: Assessment of cognitive impairment.

Univariate logistic regression for the associated risk factors with frailty in the Saudi elderly population is shown in table 6. The results of the current study revealed that, compared to subjects aged 60-65 years old, those aged $>80$ years old have more than 10 folds increased risk of frailty, with $\mathrm{OR}=10.63(95 \% \mathrm{CI} 2.95-38.28)$, and a significant $\mathrm{P}$ value of $<0.001$. For the BMI, more than two folds risk of frailty was found for subjects with a BMI of $\geq 30 \mathrm{~kg} / \mathrm{m}^{2}$, where the OR (95\% CI) was 2.64 (1.07-6.47), and a P-value of 0.034 . In addition, hypertension, dyslipidemia, heart failure, osteoporosis, and hypothyroidism were significant (all P values were $<0.05$ ) risk factors for frailty with OR of 1.87, 2.60, 6.95, 2.15, and 2.63, respectively. Moreover, polypharmacy was found to be a significant $(\mathrm{P}<$ 0.001 ) risk factor for frailty( $\mathrm{OR}=3.03,95 \% \mathrm{CI}(1.75-5.24)$.

When multivariate logistic regression analysis was done, the risk factors that remained significantly associated with frailty among the elderly Saudi population were age $>80$ years, dyslipidemia, heart failure, hypothyroidism, and polypharmacy, as shown in table 7.

\begin{tabular}{|c|c|c|c|c|c|c|c|c|}
\hline & & \multicolumn{2}{|c|}{ Robust } & \multicolumn{2}{|c|}{ Pre-frail } & \multicolumn{2}{|c|}{ Frail } & \multirow{2}{*}{$P$ value } \\
\hline & & Number & $\%$ & Number & $\%$ & Number & $\%$ & \\
\hline \multirow{5}{*}{ Age } & $60-65$ & 59 & 61.46 & 24 & 25.00 & 13 & 13.54 & \multirow{5}{*}{$0.001^{*}$} \\
\hline & $66-70$ & 28 & 50.91 & 13 & 23.64 & 14 & 25.45 & \\
\hline & $71-75$ & 20 & 47.62 & 9 & 21.43 & 13 & 30.95 & \\
\hline & $76-80$ & 4 & 33.33 & 3 & 25.00 & 5 & 41.67 & \\
\hline & $>80$ & 3 & 13.04 & 7 & 30.43 & 13 & 56.52 & \\
\hline \multirow{3}{*}{ BMI } & $<25$ & 17 & 65.38 & 6 & 23.08 & 3 & 11.54 & \multirow{3}{*}{0.135} \\
\hline & $25-29.9$ & 54 & 54.55 & 22 & 22.22 & 23 & 23.23 & \\
\hline & $35-39.9$ & 43 & 41.75 & 28 & 27.18 & 32 & 31.07 & \\
\hline \multirow{2}{*}{ Gender } & Male & 61 & 51.69 & 29 & 24.58 & 28 & 23.73 & \multirow{2}{*}{0.810} \\
\hline & Female & 53 & 48.18 & 27 & 24.55 & 30 & 27.27 & \\
\hline \multirow{5}{*}{$\begin{array}{l}\text { Education } \\
\text { level }\end{array}$} & illiterate & 50 & 47.62 & 26 & 24.76 & 29 & 27.62 & \multirow{5}{*}{$0.039 *$} \\
\hline & Primary & 19 & 34.55 & 17 & 30.91 & 19 & 34.55 & \\
\hline & Elementary & 25 & 60.98 & 10 & 24.39 & 6 & 14.63 & \\
\hline & High-school & 13 & 68.42 & 2 & 10.53 & 4 & 21.05 & \\
\hline & Higher education & 7 & 87.50 & 1 & 12.50 & 0 & 0.00 & \\
\hline \multirow{2}{*}{ Living Status } & Alone & 0 & 0.00 & 1 & 50.00 & 1 & 50.00 & \multirow{2}{*}{0.364} \\
\hline & Family & 114 & 50.44 & 55 & 24.34 & 57 & 25.22 & \\
\hline \multirow{2}{*}{ Care giver } & Yes & 22 & 30.14 & 14 & 19.18 & 37 & 50.68 & \multirow{2}{*}{$<0.001^{*}$} \\
\hline & No & 92 & 59.35 & 42 & 27.10 & 21 & 13.55 & \\
\hline \multirow{2}{*}{ Smoking } & Yes & 5 & 83.33 & 1 & 16.67 & 0 & 0.00 & \multirow{2}{*}{0.213} \\
\hline & No & 109 & 49.10 & 55 & 24.77 & 58 & 26.13 & \\
\hline
\end{tabular}

Table 5: Prevalence of frailty among the Saudi Elderly population by characteristics of the participants.

* Significant $\mathrm{p}$ value. 


\begin{tabular}{|c|c|c|c|c|c|}
\hline & & \multirow{2}{*}{ Odds Ratio } & \multicolumn{2}{|c|}{ 95\% C.I. } & \multirow{2}{*}{ P value } \\
\hline & & & Lower & Upper & \\
\hline \multirow{5}{*}{ Age } & $60-65^{* *}$ & 1.00 & & & \\
\hline & $66-70$ & 1.54 & 0.79 & 3.00 & 0.208 \\
\hline & $71-75$ & 1.75 & 0.84 & 3.65 & 0.132 \\
\hline & $76-80$ & 3.19 & 0.90 & 11.34 & 0.073 \\
\hline & $>80$ & 10.63 & 2.95 & 38.28 & $<0.001^{*}$ \\
\hline \multirow{3}{*}{ BMI } & $<25^{* *}$ & 1.00 & & & \\
\hline & $25-29.9$ & 1.57 & 0.64 & 3.87 & 0.323 \\
\hline & $\geq 30$ & 2.64 & 1.07 & 6.47 & $0.034^{*}$ \\
\hline \multirow{2}{*}{ Gender } & Male & 0.87 & 0.52 & 1.46 & 0.596 \\
\hline & Female $^{* *}$ & 1.00 & & & \\
\hline \multirow{2}{*}{ Care giver } & Yes & 3.39 & 1.87 & 6.13 & $<0.001^{*}$ \\
\hline & $\mathrm{No}^{* *}$ & 1.00 & & & \\
\hline \multirow{2}{*}{ Smoking } & Yes & 5.18 & 0.60 & 45.09 & 0.136 \\
\hline & $\mathrm{No}^{* *}$ & 1.00 & & & \\
\hline \multicolumn{6}{|l|}{ Comorbidities } \\
\hline DM & Yes & 2.01 & 0.98 & 4.10 & 0.056 \\
\hline HTN & Yes & 1.87 & 1.03 & 3.40 & $0.038^{*}$ \\
\hline Dyslipidemia & Yes & 2.60 & 1.39 & 4.86 & $0.003^{*}$ \\
\hline Heart failure & Yes & 6.95 & 2.32 & 20.83 & $0.001^{*}$ \\
\hline Osteoprosis & Yes & 2.15 & 1.01 & 4.56 & $0.047^{*}$ \\
\hline Hypothyroidism & Yes & 2.63 & 1.19 & 5.81 & $0.017^{*}$ \\
\hline Depression & Yes & 5.18 & 0.60 & 45.09 & 0.136 \\
\hline Polypharmacy & Yes & 3.03 & 1.75 & 5.24 & $<0.001^{*}$ \\
\hline
\end{tabular}

Table 6: Univariate logistic regression for the associated risk factors with frailty in the Saudi elderly population. *Significant $\mathrm{P}$ value.

** Used as a references.

\begin{tabular}{|l|c|c|c|c|c|}
\hline \multirow{4}{*}{} & & \multirow{2}{*}{ Odds Ratio } & \multicolumn{2}{|c|}{$95 \%$ C.I. } & \multirow{2}{*}{ P value } \\
\cline { 3 - 5 } & & & Lower & Upper & \\
\hline \multirow{4}{*}{ Age } & $60-65^{* *}$ & 1.00 & & & \\
\cline { 2 - 5 } & $66-70$ & 1.615 & .732 & 3.561 & 0.235 \\
\cline { 2 - 5 } & $71-75$ & 1.530 & .641 & 3.648 & 0.338 \\
\cline { 2 - 5 } & $76-80$ & 5.190 & 1.180 & 22.819 & $0.029 *$ \\
\cline { 2 - 5 } & $>80$ & 10.856 & 2.574 & 45.791 & $0.001^{*}$ \\
\hline \multirow{3}{*}{ BMI } & $<25^{* *}$ & 1.00 & & & \\
\cline { 2 - 5 } & $25-29.9$ & 1.224 & .442 & 3.391 & 0.697 \\
\cline { 2 - 5 } & $\geq 30$ & 1.065 & .372 & 3.049 & 0.907 \\
\hline Care giver & Yes & 6.378 & 2.920 & 13.931 & $<0.001$ \\
\cline { 2 - 5 } & No** & 1.00 & & & \\
\hline
\end{tabular}




\begin{tabular}{|l|c|c|c|c|c|}
\hline Comorbidities & & & & & \\
\hline HTN & Yes & .788 & .346 & 1.792 & 0.570 \\
\hline Dyslipidemia & Yes & 2.670 & 1.088 & 6.553 & $0.032^{*}$ \\
\hline Heart failure & Yes & 6.689 & 1.931 & 23.174 & $0.002^{*}$ \\
\hline osteoprosis & Yes & 2.304 & .918 & 5.785 & 0.076 \\
\hline Hypothyroidism & Yes & 2.946 & 1.132 & 7.668 & $0.027^{*}$ \\
\hline Polypharmacy & Yes & 2.061 & 1.019 & 4.166 & $0.044^{*}$ \\
\hline
\end{tabular}

Table 7: Multivariate logistic regression for the associated risk factors with frailty in the Saudi elderly population.

$$
\begin{aligned}
& \text { *Significant P value. } \\
& \text { ** Used as a references. }
\end{aligned}
$$

\section{Discussion}

We set out this cross-sectional survey study to assess the prevalence of frailty, and its risk factors in older adults in Riyadh, Saudi Arabia. The results revealed a frailty prevalence of $25.4 \%$, and age $>80$ years, dyslipidemia, heart failure, hypothyroidism, and polypharmacy, were the significant risk factors for frailty after multivariate regression analysis.

The prevalence of frailty reported in this study was $25.4 \%$, and such prevalence rate is noticeably higher compared to systemic review observed in 21 studies with an overall weighted average prevalence of $10.7 \%$ [20]. The prevalence of frailty among older adults in the population studied was much higher than in other studies from Malaysia at 18.3\% [21], Japan and the United States at $16.0 \%$ for each [22,23], and Taiwan at 4.9\% [24]. Also, other studies showed a lower frailty prevalence of frailty compared to this study including studies carried out in Canada (22.7\%) [25], Turkey (27.8\%) [26], and Italy (23.0\%) [27]. On the other hand, greatly higher frailty prevalence was reported in Chile (42.6\%) [28]. Such difference in frailty prevalence estimates between different studies might be due to differences in geographical, study design, age, gender, respondent characteristics, and heterogeneous frailty phenotype implementation. Follow-ups on frailty status are required, and the prevalence of frailty must be updated. If the prevalence of frailty rises, it will be a threat to the elderly as well as a warning to health care professionals, researchers, and policymakers [29].

The multivariate logistic regression analyses identified five predictors of frailty syndrome among older adults in Riyadh, Saudi Arabia. The associated factors related to frailty syndrome were age $>80$ years, dyslipidemia, heart failure, hypothyroidism, and polypharmacy. In a previous similar study from Malaysia, old age, unmarried, hospitalization in the previous year, poor self-rated health, and lower BMI were reported associated factors [21]. In line with our findings, previous studies consistently demonstrated that old age is positively associated with frailty [21,30].

A large body of evidence shows that most disorders, such as diabetes, hypertension, arthritis, and heart disease, increase the risk of frailty [31,32]. In the current study hypertension and arthritis were insignificantly correlated with frailty, while diabetes was a significant risk fak in the univariate but not the multivariate logistic regression analysis. Heart diseases in the current study showed a significant association with frailty in both univariate and multivariate analyses.

In the current study, obesity (BMI $\geq 30 \mathrm{~kg} / \mathrm{m}^{2}$ ) was found to be a significant risk for frailty in the univariate analysis. According to the theory of frailty syndrome, frailty is a wasting disorder [33,34]. Previous studies showed that BMI has a U-shaped curve on the risk of frailty and mortality, implying that both wasting disorder and obesity are strongly linked to frailty and mortality $[35,36]$.

In regards to the educational level as a risk factor for frailty, previous studies showed low educational level is a significant factor for frailty, and this was also the finding in our case, but after multivariate adjustment, the association became non-significant $[37,38]$.

The health-care system must be prepared to care for frail elderly people [39]. Although frailty can be reversed, the emphasis 
should be on the prevention, detection, and management of the risk factors associated with frailty. This is because the annual mean healthcare cost of the frail elderly is more than twice as high as the estimated cost for the robust elderly [39].

\section{Limitations}

There are some limitations in the current study. First, there is no established "gold standard" measurement of frailty in elderly patients, and we used only one tool, therefore the probability of bias is there. Second, the study was cross-sectional in design, so we cannot assess the causality. Third, the sample was taken from only one healthcare institution in Riyadh, Saudi Arabia, therefore, the results cannot be generalized to the whole kingdom. Multicenter studies with a larger sample size are warranted in the future.

\section{Conclusion}

In conclusion, the prevalence of frailty syndrome was $25.4 \%$, while $24.6 \%$ were prefrail. Possible cognitive impairment was reported in $18.4 \%$. Old age, dyslipidemia, heart failure, hypothyroidism, and polypharmacy, were the significant risk factors for frailty after multivariate adjustment. As the older adults population size in Saudi Arabia is growing with greater longevity, the impact of frailty syndrome could not be ignored and neglected. Further study is needed to validate our findings in other large-scale population of older adults.

\section{Statistical analysis}

Data were analyzed by using Statistical Package for Social Studies (SPSS 22; IBM Corp., New York, NY, USA). Descriptive statistics for Categorical variables were expressed as percentages and for continuous variables we used mean and Standard deviation. We used analytic statistics such as Chi square test was used for categorical variables. Univariate and multivariate logistic regression were used to assess the associated risk factors with frailty among the Saudi Elderly population. A p-value $<0.05$ was considered statistically significant.

\section{Bibliography}

1. Fried LP., et al. "Frailty in older adults: evidence for a phenotype". The Journals of Gerontology, Series A 56.3 (2001): M146M157.

2. De Vries NM., et al. "Outcome instruments to measure frailty: a systematic review". Ageing Research Reviews 10.1 (2011): 104-114.
3. Martin FC and Brighton P. "Frailty: Different tools for different purposes?” Age Ageing 37.2 (2008): 129-131.

4. Mohd Hamidin FA., et al. "Prevalence of frailty syndrome and its associated factors among community-dwelling elderly in East Coast of Peninsular Malaysia". SAGE Open Medical Case Report 6 (2018).

5. Clegg A., et al. "Frailty in elderly people". Lancet 381.9868 (2013): 752-762.

6. United Nations, Department of Economic and Social Affairs PD. World Population Ageing 2017. United Nations (2017): 124.

7. Collard RM., et al. "Prevalence of frailty in community-dwelling older persons: a systematic review". Journal of the American Geriatrics Society 60.8 (2012): 1487-1492.

8. Purser JL., et al. "Identifying frailty in hospitalized older adults with significant coronary artery disease". Journal of the American Geriatrics Society 54.11 (2006): 1674-1681.

9. Ekerstad N., et al. "Frailty is independently associated with short-term outcomes for elderly patients with non-ST-segment elevation myocardial infarction". Circulation 124.22 (2011): 2397-2404.

10. Andela RM., et al. "Prevalence of frailty on clinical wards: description and implications". The International Journal of Nursing Practice 16.1(2010): 14-19.

11. Chen CY., et al. "The prevalence of subjective frailty and factors associated with frailty in Taiwan". Archives of Gerontology and Geriatrics 50 (2010): S43-S47.

12. Avila Funes JA., et al. "Cognitive impairment improves the predictive validity of the phenotype of frailty for adverse health outcomes: the threecity study". Journal of the American Geriatrics Society 57.3 (2009): 453-461.

13. Syddall H., et al. "Prevalence and correlates of frailty among community-dwelling older men and women: findings from the Hertfordshire Cohort Study". Age Ageing 39.2 (2009): 197203.

14. Fried LP., et al. "Untangling the concepts of disability, frailty, and comorbidity: implications for improved targeting and care". The Journals of Gerontology, Series A 59.3 (2004): M255M263.

15. Bales CW and Ritchie CS. "Sarcopenia, weight loss, and nutritional frailty in the elderly". Annual Review of Nutrition 22.1 (2002): 309-323. 
16. Gleason L., et al. "FRAIL Questionnaire Screening Tool and Short-Term Outcomes in Geriatric Fracture Patients". Journal of the American Medical Directors Association 18.12 (2017): 1082-1086.

17. Borson S., et al. "The mini-cog: a cognitive "vital signs" measure for dementia screening in multi-lingual elderly". International Journal of Geriatric Psychiatry 15.11 (2000): 1021-1027.

18. Alqahtani BA and Nasser TA. "Assessment of frailty in Saudi community-dwelling older adults: validation of measurements". Annals of Saudi Medicine 39.3 (2019): 197-204.

19. Albanna M., et al. "Validation and cultural adaptation of the Arabic versions of the Mini-Mental Status Examination - 2 and Mini-Cog test". Neuropsychiatric Disease and Treatment 13 (2017): 793-801.

20. Collard RM., et al. "Prevalence of frailty in community-dwelling older persons: a systematic review". Journal of the American Geriatrics Society 60.8 (2012): 1487-1492.

21. Mohd Hamidin FA., et al. "Prevalence of frailty syndrome and its associated factors among community-dwelling elderly in East Coast of Peninsular Malaysia". SAGE Open Medical Case Reports 6 (2018).

22. Doba N., et al. "A pilot trial to predict frailty syndrome: the Japanese Health Research Volunteer Study". Experimental Gerontology 47.8 (2012): 638-643.

23. Ensrud KE., et al. "Comparison of 2 frailty indexes for prediction of falls, disability, fractures, and death in older women". Archives of internal medicine 168.4 (2008): 382-389.

24. Avila Funes JA., et al. "Cognitive impairment improves the predictive validity of the phenotype of frailty for adverse health outcomes: the threecity study". Journal of the American Geriatrics Society 57.3 (2009): 453-461.

25. Song X., et al. "Prevalence and 10-year outcomes of frailty in older adults in relation to deficit accumulation". Journal of the American Geriatrics Society 58.4 (2010): 681-687.

26. Akın S., et al. "The prevalence of frailty and related factors in community-dwelling Turkish elderly according to modified Fried Frailty Index and FRAIL scales". Aging clinical and experimental research 27.5 (2015): 703-709.

27. Alessandro Battaggia., et al. "The burden of frailty in older people visiting GPs in Veneto and Sicily, Italy". Journal of Drug Assessment 8.1 (2019): 87-96.
28. Albala C., et al. "Frequency of frailty and its association with cognitive status and survival in older Chileans". Clinical Interventions in Aging 12(2017): 995-1001.

29. Morley JE., et al. "Frailty consensus: a call to action". Journal of the American Medical Directors Association 14 (2013): 392397.

30. Heppenstall CP., et al. "Frailty: dominos or deliberation?" The New Zealand Medical Journal 122.1299 (2009): 42-53.

31. De Mello MT., et al. "Relationship between physical activity and depression and anxiety symptoms: a population study". The Journal of Affective Disorders 149.1-3 (2013): 241-246.

32. Fried LP., et al. "Frailty in older adults: evidence for a phenotype". The Journals of Gerontology, Series A 56.3 (2001): M146M157.

33. Hubbard RE., et al. "Frailty, body mass index, and abdominal obesity in older people". The Journals of Gerontology, Series A 65.4 (2009): 377-381.

34. Blaum CS., et al. "The association between obesity and the frailty syndrome in older women: the Women's Health and Aging Studies". Journal of the American Geriatrics Society 53.6 (2005): 927-934.

35. Cesari M., et al. "Frailty syndrome and skeletal muscle: results from the Invecchiare in Chianti study". The American Journal of Clinical Nutrition 83.5 (2006): 1142-1148.

36. Flicker L., et al. "Body mass index and survival in men and women aged 70 to 75". Journal of the American Geriatrics Society 58.2 (2010): 234-241.

37. Eyigor S Frailty., et al. "Prevalence and related factors in the older adult-frail TURK project”. Age 37.3 (2015): 9791.

38. Liang YD., et al. "Identification of Frailty and Its Risk Factors in Elderly Hospitalized Patients from Different Wards: A CrossSectional Study in China". Clinical Interventions in Aging 14 (2019): 2249-2259.

39. Salinas Rodríguez A., et al. "Healthcare costs of frailty: implications for long-term care". Journal of the American Medical Directors Association 20 (2019): 102-103.

\section{Volume 5 Issue 12 December 2021 (c) All rights are reserved by Abdulmalik Almufarrih., et al.}

